\title{
Notes
}

\section{Interaction of Sulfur-Loaded 3A Zeolite with Ethylene}

The sulfur-loaded 3A clay-bond molecular sieve exposed to ethylene at temperatures higher than $190^{\circ} \mathrm{C}$ loses its sulfur. Mainly hydrogen sulfide is formed. This behavior restricts its use as a cracking catalyst.

\section{INTRODUCTION}

Dudzik and Preston (1) reported about sulfurimpregnated type A Linde molecular sieves and suggested their use as cracking catalysts.

The narrow pores of the $3 \mathrm{~A}$ zeolite allow the entrance of open sulfur chains during the loading, thus causing strong paramagnetism.

We used the impregnated $3 \mathrm{~A}$ molecular sieve (pore diam, $0.3 \mathrm{~nm}$ ) to study reactions between ethylene and sulfur radicals. The olefine molecule has a diameter of $0.425 \mathrm{~nm}$ and therefore cannot enter into the pores of this zeolite (2). The head of the trapped sulfur chain radical may be exposed for interaction with ethylene.

\section{EXPERIMENTAL PART}

\subsection{Impregnation of the Molecular Sieve $3 A$ (Union Carbide, $1 / 16$ in. Pellets)}

The sulfur was recrystallized from carbon disulfide and freed from gaseous impurities in vacuum $(0.1 \mathrm{~mm} \mathrm{Hg})$ at $150^{\circ} \mathrm{C}$ during $3 \mathrm{hr}$.

The zeolite was loaded with sulfur vapor at $400^{\circ} \mathrm{C}$ as described by Dudzik and Preston (1). The sulfur-impregnated sieve will be indicated as $3 \mathrm{AS}$ before the reaction with ethylene and as 3 AS' after the experiment.

\subsection{Reaction Conditions}

A mixture of ethylene (4 liters/hr) and nitrogen (9 liters $/$ hr) was fed into a Pyrex reactor of the flow type which contained $6 \mathrm{~g}$ of the sieve. The temperature ranged from 20 to $300^{\circ} \mathrm{C}$. The gases leaving the reactor were analyzed by gLC. Solid products were dissolved in carbon disulfide and subjected to NMR analysis.

\subsection{Apparalus}

An Aerograph 700 was used for gLC analysis. Column: $6 \mathrm{ft}, 1 / 4$ in. o.d., stainless steel; polypak I (80-120 mesh); detector: thermal conductivity cell; carrier gas: He.
The ESR measurements were performed on a Varian E3 spectrometer at $25^{\circ} \mathrm{C}$.

A Varian HR $100 \mathrm{~A}$ was used for NMR analysis.

\section{RESULTS AND DISCUSSION}

At temperatures below $190^{\circ} \mathrm{C}$ the gases leaving the reactor consisted only of ethylene and nitrogen. When the temperature was raised, gLC analysis showed the appearance of hydrogen sulfide, carbon sulfide and traces of a third compound, presumably ethanethiol. As the time went on the concentration of these compounds decreased, while. the blue-grey color of the zeolite turned into the original appearance, as before the loading with sulfur. Ethylene sulfide was not formed.

In the cooler parts of the reactor small amounts of a sublimate settled, which were soluble in carbon disulfide. The NMR spectrum of this solution showed a broad signal at $\delta 3.35 \mathrm{ppm}$. It is ascribed to the formation of poly (alkylene polysulfides) $(5,6)$. The signal agrees with the NMR, spectrum of poly (ethylene tetrasulfide) prepared according to the method of Patrick $(3,4)$.

ESR spectra of the molecular sieve before and after the loading with sulfur and after the experiment are summarized in Table I.

The signals 1, 2 and 3 are due to the unloaded zeolite (3A). The same pattern is shown by $4 \mathrm{~A}$ and $5 \mathrm{~A}$. The signals may be caused by paramagnetic metal ions in the clay binder. The decrease of signals 2 and 3 after loading may be an indication for interaction between the sulfur radicals and the original radicals in the unloaded system. Dudzik and Preston (1) used powdered pure 3A. The identity of the signals 4 and 5 is obscure.

The ESR spectrum of the freshly loaded sieve (3AS) is not identical with Dudzik and Preston's (1). Although the difference in position between our signal No. 6 (2.026) and Dudzik and Preston's (2.0286) is small, the line widths do not agree: 5 and $50 \mathrm{G}$, respectively. Both signals are ascribed to polysulfur radicals. The difference in width may be explained by assuming that the clay-bond sieve was not fully saturated with long sulfur chains.

During the exposure of the sulfur-loaded zeolite to ethylene at elevated temperatures hydrogen sulfide is formed. The strong decrease of the ESR 
TABLE I

Intenstities of ESR Signals of Zeolites Before (3A, 4A, 5A) and After Loading with Sulfur (3AS, 4AS) and After Reaction with Ethylene (3AS')

\begin{tabular}{llcccccc}
\hline & \multicolumn{7}{c}{ Signal intensity (mm) } \\
\cline { 3 - 7 } Zeolite & $\begin{array}{l}\text { Signal no.: } \\
\text { g (relative to DPPH) : }\end{array}$ & 1 & 2 & 3 & 4 & 5 & 6 \\
& Line width: & 3.09 & 2.15 & 2.000 & 2.003 & 2.008 & 2.026 \\
\hline $3 \mathrm{~A}$ & 50 & 1000 & 10 & 6 & 6 & 5 \\
$4 \mathrm{~A}$ & 49 & 53 & 27 & 0 & 0 & 0 \\
$5 \mathrm{~A}$ & 37 & 23 & 20 & 0 & 0 & 0 \\
$3 \mathrm{AS}$ & 23 & 42 & 12 & 0 & 0 & 0 \\
$4 \mathrm{AS}$ & 42 & 6 & 0 & 0 & 1 & 670 \\
$3 \mathrm{AS}^{\prime}$ & 26 & 3 & 0 & 0 & 1 & 107 \\
& 41 & 10 & 0 & 79 & 0 & 31 \\
\hline
\end{tabular}

signal at 2.026 agrees with the return of the original appearance of the sieve before the loading with sulfur. This behavior proves that the zeolite loses its internal sulfur. Dudzik and Preston (1) did not observe an appreciable decrease of ESR signal intensity after their experiments with fully saturated $3 \mathrm{~A}$ sieve.

Their olefin mixture formed in cracking experiments did not contain ethylene, although, in general ethene is a component cracking gases. This olefin might have been formed, but converted to hydrogen sulfide, organic sulfur compounds ete. The formation of hydrogen sulfide might have escaped their gLC detection, because this compound shows little or no response in the flame ionization detector (7), which was used by Dudzik and Preston (1).

Therefore it is concluded that sulfur loaded clay-bond 3A molecular sieve can have only a limited applicability as a cracking catalyst.

\section{ACKNOWLEDGMENTS}

These investigations have been carried out as part of a research project sponsored by AKZO Research and Engineering N. V. The author is indebted to Dr. A. Mackor for performing the ESR experiments at the Laboratory for Organic Chemistry of the Municipal University of Amsterdam. Professor Dr. W. Drenth is thanked for the helpful discussions and for constructively criticizing the script. Acknowledgment is made also to Miss E. C. T. Gevers and Dr. C. W. Pluijgers for reading the manuscript and for their important advices.

\section{REFERENCES}

1. Dudzik, Z., and Preston, K. F., J. Colloid Interface Sci. 26, 374 (1968).

2. BeCK, D. W., J. Amer. Chem. Soc. 78, 5963 (1965).

3. Patrick, J. C., Trans. Faraday Soc. 32, 347 (1936).

4. Fitch, B. M., and Helgeson, D. C., J. Polym. Sci., Part C 22, 1101 (1966).

5. Bateman, L., Moore, C. G., and Kharasch, N. (ed.), "Organic Sulfur Compounds," Vol. 1, p. 215. Pergamon, N.Y. 1961.

6. Lüttringhaus, A., König, H. B., and BötTCHER, B., Justus Liebigs Ann. Chem. 560, 201 (1948).

7. Dal Nogare, S., and Juvet, R. S., JR., "GasLiquid Chromatography, Theory and Practice," p. 222. Wiley (Interscience), New York, 1962.

H. J. Munter

Institute for Organic Chemistry TNO

Croesestraat 79 ,

Utrecht, The Netherlands

Received February 9, 1972; accepted July 11, 1972 